\title{
Calorie restriction and stroke
}

\author{
Silvia Manzanero', Mathias Gelderblom², Tim Magnus² and Thiruma V Arumugam ${ }^{\text {1* }}$
}

\begin{abstract}
Stroke, a major cause of disability and mortality in the elderly, occurs when a cerebral blood vessel is occluded or ruptured, resulting in ischemic damage and death of brain cells. The injury mechanism involves metabolic and oxidative stress, excitotoxicity, apoptosis and inflammatory processes, including activation of glial cells and infiltration of leukocytes. In animal models, dietary energy restriction, by daily calorie reduction (CR) or intermittent fasting (IF), extends lifespan and decreases the development of age-related diseases. Dietary energy restriction may also benefit neurons, as suggested by experimental evidence showing that CR and IF protect neurons against degeneration in animal models. Recent findings by our group and others suggest the possibility that dietary energy restriction may protect against stroke induced brain injury, in part by inducing the expression of neurotrophic factors, such as brain-derived neurotrophic factor (BDNF) and basic fibroblast growth factor (bFGF); protein chaperones, including heat shock protein 70 (Hsp70) and glucose regulated protein 78 (GRP78); antioxidant enzymes, such as superoxide dismutases (SOD) and heme oxygenase-1 (HO-1), silent information regulator T1 (SIRT1), uncoupling proteins and anti-inflammatory cytokines. This article discusses the protective mechanisms activated by dietary energy restriction in ischemic stroke.
\end{abstract}

Keywords: calorie restriction, intermittent fasting, stroke, ischemia, brain

\section{Introduction}

In the western world the average calorie intake has steadily risen as have associated diseases. Calorie restriction $(\mathrm{CR})$ is defined as a decrease in energy intake without lowering nutritional value. This simple intervention has shown, in a wide range of laboratory animals, to extend lifespan and decrease the incidence of several age-related diseases [1]. In humans, CR can reduce markers of oxidative stress and inflammation $[2,3]$, and can lower cardiovascular disease risk [4]. Dietary energy restriction also benefits neurons, as suggested by data showing that $C R$ protects neurons against dysfunction and degeneration in animal models of epileptic seizure, stroke and neurodegenerative diseases $[5,6]$.

The risk of ischemic stroke, the second major cause of morbidity and mortality worldwide, can be reduced through diet and lifestyle modification [7]. The mechanisms responsible for neuronal death caused by stroke are believed to involve metabolic compromise, over activation of glutamate receptors, cellular calcium overload, oxidative stress and inflammation [8]. Studies using in vivo and in

\footnotetext{
* Correspondence: t.arumugam@uq.edu.au

'School of Biomedical Sciences, The University of Queensland, St Lucia, QLD 4072, Australia

Full list of author information is available at the end of the article
}

vitro stroke models have identified several proteins and signalling pathways that can protect neurons against ischemic injury, including: neurotrophic factors, such as brain-derived neurotrophic factor (BDNF) and glial cell line-derived neurotrophic factor (GDNF); protein chaperones, including heat shock protein 70 (Hsp70) and glucose regulated protein 78 (GRP78); antioxidant enzymes, such as heme oxygenase-1 (HO-1) and the regulator of mitochondrial biogenesis PGC-1 $\alpha$. Several studies suggest CR may promote neuronal survival and plasticity in ischemic stroke, by inducing neuroprotective factors and suppressing inflammatory pathways. The present article reviews findings supporting the neuroprotective effects of CR and discusses the mechanisms activated by $\mathrm{CR}$ in ischemic stroke.

\section{Calorie Restriction}

Experiments performed seven decades ago showed that CR increases the lifespan of rodents $[9,10]$, and this has been widely replicated and extended, demonstrating an increase in both the mean and maximum lifespan of rats and mice maintained on CR [11-14]. More recently, it was shown that CR also slows aging in monkeys [15]. A number of physiological effects of CR that may contribute to its ability to increase lifespan have been documented in 
animal studies. Important among these are the preservation of metabolic functions despite aging [16], reduced body temperature and levels of oxidative stress $[17,18]$, increased resistance to various types of stress [19], and enhanced immune function [20,21].

Another form of dietary stress studied alongside CR is intermittent fasting (IF). In rodents, it consists of alternating days of ad libitum feeding with days when only water is made available to the animals [22]. Human IF has involved alternating days eating less and more than the recommended daily energy intake [23]. CR and IF can improve risk factors for diabetes and cardiovascular disease in rodents [22-24], as well as delay, prevent or treat conditions responsible for mortality in rodents such as cancers and kidney disease [25-27]. When maintained on a CR or an IF diet, organisms ranging from yeast to monkeys exhibit increased resistance to many different types of stressors [19]. This is associated with increased resistance of cells in many different tissues to injury induced by oxidative, genotoxic and metabolic insults. The conservation of stress resistance responses to CR and IF across a range of species provides strong evidence that this mechanism contributes to the lifespan-extending action of dietary restriction.

\section{Cellular and molecular mechanisms underlying effects of calorie restriction on the brain Reduced oxidative damage}

Mitochondrial ROS such as superoxide and peroxide anions, and their products, are a result of mitochondrial oxidative phosphorylation and cause oxidative damage to proteins, lipids and DNA. Accordingly, ageing is believed to be in large part due to cumulative damage caused by mitochondrial ROS [28], and an inverse correlation has been found between ROS production and longevity across mammalian species [29]. The brain is particularly susceptible to oxidative stress because of the high level of mitochondrial activity and the presence of heavy metal ions that can act as catalysts of oxidative reactions. Besides, the abundance of lipids in the nervous system makes them a prime target of oxidative damage. Hence, lipid peroxidation plays an important role in many neurodegenerative and psychiatric disorders [30]. Moreover, damaged molecules tend to accumulate in long-lived, post-mitotic neurons [31], making the situation worse and providing a connection between age and oxidative stress in the brain. In stroke, markers of oxidative damage to lipids and proteins have been found in animal models as well as in human patients, and levels of some of them correlate to stroke severity [32,33].

There is evidence that both CR and IF prevent oxidative damage by three major mechanisms: diminished production of mitochondrial reactive oxygen species (ROS), increased antioxidant defences and increased repair mechanisms for molecules that have been damaged as a result of oxidation [34]. Several studies have shown low levels of mitochondrial ROS generation in various tissues of $C R$ rodents including the brain $[35,36]$. There is evidence that this is due to a mild enhancement of the mitochondrial respiratory rate, resulting in lower ROS release. Recent studies provided substantial evidence to confirm the link between respiratory rate, ROS release [37] and aging [38] by causing mild uncoupling in the passage of protons through the inner mitochondrial membrane from mitochondrial phosphorylation. This uncoupling is partly mediated by the so-called uncoupling proteins (UCP), whose levels are increased by $C R$ in various tissues, including the neuron-specific UCP4 (Figure 1) [39]. There is evidence for the neuroprotective effects of UCP2, UCP4 and

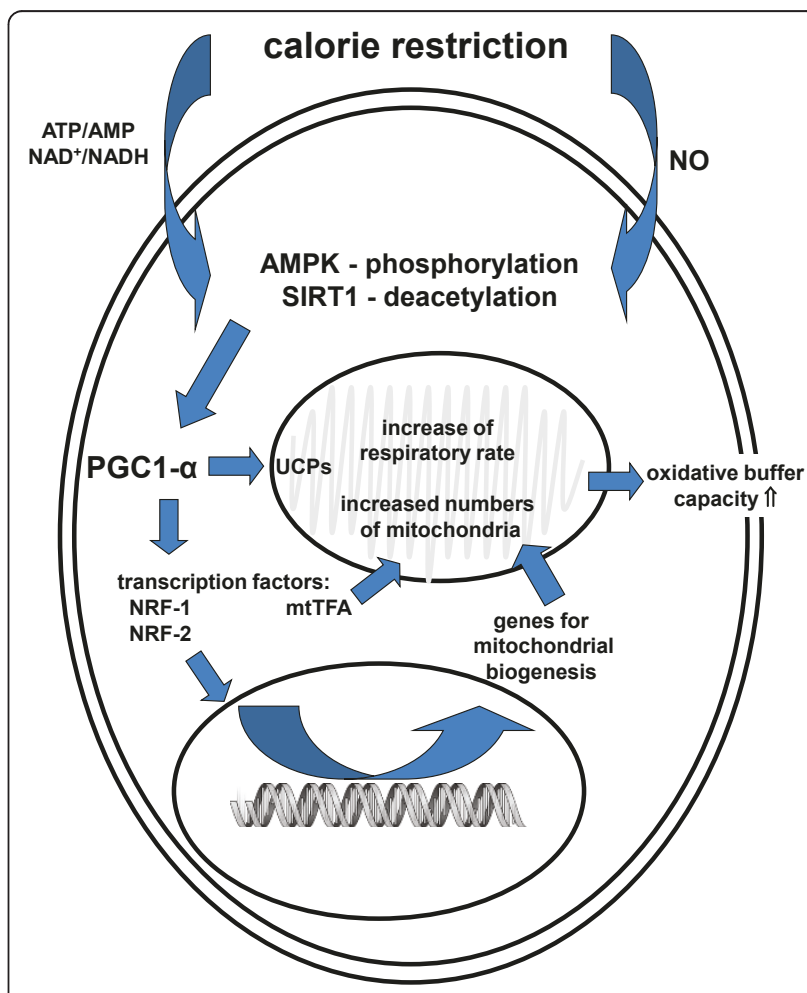

Figure 1 Pathways of calorie restriction leading an increased metabolic rate. Cells are sensitive to energy levels through molecules that detect ATP/AMP and $\mathrm{NAD}^{+} / \mathrm{NADH}$ ratios. Energy deficiency will activate the enzymes AMPK and SIRT1, which is also activated by NO, and through their respective phosphorylation and deacetylation, the activity of numerous substrates involved in metabolic functions will be modified. One of these is PGC-1 $\alpha$, which activates the transcription factors NRF-1 and -2 and mtTFA. The former two activate nuclear transcription of genes for mitochondrial biogenesis and the latter does the same in the mitochondria. This accounts for an increase in the numbers and size of mitochondria as well as an enhancement in the respiratory rate. All of these changes elevate the oxidative buffer capacity of the cell, augmenting its resistance to conditions of stress. 
UCP5; however, their effects seem to encompass more than just mild uncoupling of the mitochondrial membrane and in some cases they appear to mediate protection through totally different mechanisms [40-43].

ROS scavengers, such as superoxide dismutase, glutathione peroxidase and catalase among others, are essential for antioxidant defence [44]. However, their levels or activity do not seem to be greatly affected by CR $[45,46]$. As for repair mechanisms for ROS-damaged molecules, it has been shown that $C R$ reduces transcription levels of protein and DNA repair genes in skeletal muscle, but this seems to be partly a response to the lower damage caused by a lower metabolic rate [45]. An exception to this is the enzyme heme oxygenase-1 (HO-1), which is induced in various cell types by many stressful stimuli, including IF [47], and has anti-oxidant, anti-inflammatory and antiapoptotic activities, which have been shown to contribute to mouse brain protection from focal ischemia [47]. Overall it seems, however, that the reduction of ROS produced in the mitochondria might be the most relevant mediator of CR-induced effects.

\section{Increased mitochondrial biogenesis}

How CR decreases the metabolic rate in order to lower oxidative stress is not well understood. Moreover, this is in apparent contradiction with another CR effect, which is its proved ability to increase the number and promote the activity of mitochondria. A key mediator of these effects is the peroxisome proliferator-activated receptor $\gamma$ (PPAR $\gamma$ ) coactivator $1 \alpha$ (PGC-1 $\alpha$ ), a protein central to mitochondrial biogenesis, whose activity explains the coordination of mitochondrial processes by environmental factors. PGC-1 $\alpha$ is regulated through many mechanisms, of which AMP-activated protein kinase (AMPK) phosphorylation and silent information regulator T1 (SIRT1) deacetylation seem to be the most likely candidates to mediators of CR [48]. AMPK is activated by changes in the ATP/AMP ratio, whereas SIRT1 is activated by nicotinamide, which shows its dependence on $\mathrm{NAD}^{+} / \mathrm{NADH}$ balance. Both of these enzymes are, therefore, in tune with energy levels, showing them as prime targets for CR. In fact, CR has been shown to increase the activity of both AMPK and SIRT1, resulting in increased levels and activity of PGC$1 \alpha$ (Figure 1). SIRT1 is also activated by NO, another putative target of CR [49]. PGC-1 $\alpha$ mediates processes relevant to mitochondrial biogenesis, including: i) up-regulation of transcription factors that activate transcription of mitochondrial genes in the nucleus, such as NRF-1 and NRF-2; ii) induction of transcription and replication of the mitochondrial genome, mediated by the mitochondrial transcription factor mtTFA, which is in turn activated by NRF-2. Besides, PGC- $1 \alpha$ induces UCPs [50], which in turn result in lower ROS release. Therefore, CR does not seem to decrease the metabolic rate, as was formerly thought, but it appears to actually increase it [51], and this increase is responsible for its buffering effects on oxidative stress (Figure 1).

Corresponding to its beneficial effects on cell metabolism, PGC-1 $\alpha$ deficiency is believed to mediate the neurodegenerative effects of $\mathrm{AD}, \mathrm{HD}$ and $\mathrm{PD}$, as decreased levels of this molecule were found in post-mortem analysis of patients [52-54]. Accordingly, PGC-1 $\alpha$ and another member of the family, PGC-1 $\beta$, have been reported to control mitochondrial density in neurons and reduce oxidative stress [55]. Despite the accumulating evidence of the effects of CR and PGC-1 $\alpha$ on mitochondrial biogenesis, one study has claimed not to have found such increase, with levels of PGC-1 $\alpha$ and essential mitochondrial proteins unchanged after 14 weeks of CR in rats [56]. These results only highlight how complex the mechanisms are that mediate CR effects and how far we are from elucidating how the process works.

\section{Increased cellular stress resistance}

Another neuroprotective mechanism of CR is based on its putative effects as a mild stressor, activating cellular stress response pathways with upregulation of neurotrophic factors and heat-shock proteins, which in turn make the cells more resistant to neurodegeneration and ischemic insults. This is known as a preconditioning, or hormetic, effect, or the ability of a sublethal stressor to protect an organ from a subsequent lethal injury. The following molecules have been found to be up-regulated and mediate some of the effects of CR and IF in the mammalian brain.

\section{Neurotrophic factors}

Brain derived neurotrophic factor (BDNF) has been shown to be up-regulated by CR and IF in rodent and primate brain [47,57-59], whereas human evidence is still pending [60]. In a model of seizure, injection of BDNF blocking antibody reduced the positive effects of $\mathrm{CR}$, demonstrating this molecule's essential role mediating the effects of CR in protection from excitotoxicity $[57,58]$. BDNF is a versatile neurotrophin with a central role in synaptic plasticity and consequently learning and memory. Its levels are very closely linked with diet, so that when food intake is high, and particularly if it is high in saturated fat, energy metabolism increases resulting in high production of ROS. Oxidative stress down-regulates BDNF, and thus negatively affects synaptic plasticity [61]. BDNF also has a function in turning down energy metabolism, so the effect is amplified. Conversely, CR or IF decrease oxidative stress, and this leads to the up-regulation of BDNF, resulting in increased synaptic plasticity. BDNF signals through the TrkB (tyrosine kinase) receptor, activating the Trk kinases which trigger a number of signalling pathways, including PLC (phospholipase C) $\gamma$, PI3K (Phosphatidylinositol 3 Kinase) and the MAPK (mitogen activated protein kinase) pathway [62]. The resulting gene expression 
promotes synaptic plasticity, neurogenesis and cell survival. It is not surprising that BDNF is important in the protection from neurodegenerative diseases, such as PD and $\mathrm{AD}[63]$ and in the recovery from stroke (see below).

Glial cell line-derived neurotrophic factor (GDNF) has an important role in PD because it promotes survival of dopaminergic neurons whose malfunction accounts for the symptoms of the disease, and it also has a general role in the protection and development of many types of neurons (reviewed in [64]). Just as BDNF, GDNF signals through PLC $\gamma$, PI3K and MAPK pathways, and in fact these two neurotrophic factors seem to act in synergy, although it has been shown that BDNF has more powerful effects in the protection of dopaminergic neurons [65]. Neurotrophic factors and oxidative stress seem to be mutually negative regulators, because neurotrophins lower oxidative stress by up-regulating antioxidant proteins, providing an indirect role of CR on antioxidant functions. On the other side, oxidative stress down-regulates neurotrophins, providing a feedback loop that can be activated by high food consumption and is detrimental for the cell [66].

\section{Heat-shock proteins}

The main member of this family affected by CR is heatshock protein (Hsp) 70. Levels of this chaperone in the rat brain have been shown to decrease with age up to $75 \%$ [67], and CR and IF can increase them $[47,68]$. Besides its role in protein folding, Hsp70 offers neuroprotection with its anti-apoptotic role downstream of cytochrome $\mathrm{c}$ and upstream of caspase-3 [69], and its role in the preservation of energy transfer in case of impaired mitochondrial metabolism [70]. Hsp70 is induced after a central nervous system insult, including seizure [71] and excitotoxic, oxidative and metabolic insults [68], which provides evidence for the role of this protein in the recovery from brain injury.

Glucose-regulated protein (GRP) 78 is a stress-induced chaperone in the endoplasmic reticulum, and as such it enhances the secretion rate and efficiency of specific proteins [72]. Besides, GRP78 promoter is enhanced in conditions of low glucose or oxygen, which are characteristic of ischemia and tumours. As a consequence of its function in the protection from protein misfolding, GRP78 has anti-apoptotic functions in neurons [73]. Like Hsp70, levels of GRP78 in brain have been seen to decrease with age [47], whereas they increase substantially under CR and IF conditions $[47,68]$.

\section{Enhanced autophagy}

Autophagy refers to the cellular process by which longlived proteins and whole organelles get sequestered and degraded by lysosomes [74]. It is an essential process for the health of long-lived cells such as neurons, and, therefore, it is fundamental for the maintenance of the nervous system. Autophagy is heavily involved in synaptic growth and plasticity in Drosophila [75] and its disregulation has been linked to neurodegenerative diseases such as AD, PD and HD [76]. Autophagy is induced by oxidative stress via the activity of PI3K [77], and strongly inhibited by the mammalian target of rapamycin (mTOR, [78]). Even short term CR is known to enhance autophagy in neurons [79], and this is primarily mediated by inhibition of mTOR. Like PGC- $1 \alpha$, this molecule forms a nexus between diet and cellular changes, because of its ability to sense cellular ATP/ AMP ratios, through its inhibition by AMPK, insulin and amino acid levels [80]. mTOR is down-regulated by $\mathrm{CR}$ and its inhibition plays an essential role in CRmediated positive effects, including delayed aging, synaptic plasticity and delayed neurodegeneration, and most of these effects are mediated by its regulation of autophagy.

\section{Reduced inflammation}

Inflammation, the complex, somehow nonspecific, process by which the body combats infection, is currently proving to have a dark side for it can have powerful negative effects in many non-infection mediated medical conditions. The presence of inflammation, even at low levels, can worsen the outcome of obesity, stroke, neurodegenerative and other diseases. Moreover, some chronic conditions arise as a result of unwanted inflammation, such as type II diabetes. Levels of inflammatory markers, such as C-reactive protein, tumor necrosis factor (TNF) and interleukin 6 (IL-6), increase with age and obesity, and decrease accordingly with CR [81], and the mediators of this decline are various, including the already mentioned Hsp70, PGC$1 \alpha$ and neurotrophic factors such as BDNF, but here we will focus on two key proteins involved which are SIRT1 and $\mathrm{mTOR}$.

SIRT1

One of the substrates of the deacetylase SIRT1 is the nuclear factor $\kappa \mathrm{B}(\mathrm{NF} \kappa \mathrm{B})$ subunit RelA which when deacetylated shows decreased ability to enhance transcription after TNF stimulation [82]. Because NF $\kappa \mathrm{B}$ is the central transcription factor responsible for expression of many genes involved in inflammation, SIRT1 inhibits inflammation, and direct evidence of its activity has been shown in neuronal death by microglia inflammatory response to amyloid- $\beta$ [83]. This immunoregulatory effect of SIRT1 adds to the list of advantageous effects of the enzyme which is strongly up-regulated by CR.

\section{mTOR}

The inhibition of mTOR has a dramatic effect in the suppression of inflammation, and in fact rapamycin, the drug from which it gets its name, has a strong immunosuppressive effect and it is currently used to minimize transplant rejection. This is due to the fact that mTOR, 
which is activated by the PI3K/Akt pathway, promotes cell growth and proliferation, cytokine production and signalling, all of which are essential for an efficient immune response [84].

\section{Molecular mechanisms of ischemic stroke induced brain injury \\ Excitotoxicity}

A significant proportion of ischemia-induced neuronal damage is mediated by toxic accumulation of excitatory amino acids. The lack of energy caused by the interruption of cerebral blood flow leads to failure of ion pumps, which results in inwards diffusion of calcium and sodium across the membrane along their concentration gradients, causing cellular swelling and depolarization [85]. Elevations of intracellular sodium become toxic and can contribute to necrotic neuronal death at early time points (minutes to hours) after ischemia. Elevations of calcium, however, activate ionotropic glutamate receptors. Glutamate, which is the major excitatory neurotransmitter in the brain, accumulates in the extracellular space and activates AMPA/ kainate and NMDA receptors. Calcium ions enter the cell through these voltage-dependent and ligand-gated ion channels, resulting in the activation of a number of proteases, kinases, lipases and endonucleases, culminating in apoptosis $[86,87]$. It has been suggested that many neurons, particularly those in the ischemic penumbra, die by this mechanism involving glutamate-induced calcium influx [88].

\section{Oxidative damage}

Neurons are normally exposed to baseline levels of oxidative stress, caused by free radicals from both exogenous and endogenous sources. These are highly reactive molecules with one or more unpaired electrons, which can react with DNA, proteins and lipids causing varying degrees of damage and dysfunction. Numerous experimental and clinical studies have documented increased levels of oxidative stress during all forms of stroke injury. Free radicals involved in stroke-induced brain injury include superoxide anion radical, hydroxyl radical and nitrous oxide (NO). Mitochondria are the primary source of ROS during ischemic or hemorrhagic stroke injury, which produce superoxide anion radicals during the electron transport process. Another potentially important source of superoxide in post-ischemic neurons is the metabolism of arachidonic acid through the cyclooxygenase and lipooxygenase pathways [89]. Following reperfusion in ischemic injury, ROS is also generated by activated microglia and infiltrating peripheral leukocytes via the nicotinamide adenine dinucleotide phosphate (NADPH) oxidase system [90]. $\mathrm{NO}$ is generated from $\mathrm{L}$-arginine through one of several nitric oxide synthase (NOS) isoforms. The neuronal form of NOS, which requires calcium/calmodulin for activation, is produced by subpopulations of neurons throughout the brain [85]. Inducible NOS (iNOS) is produced by inflammatory cells, such as microglia and monocytes. These two isoforms are, for the most part, damaging to the brain under ischemic conditions, however a third isoform of NOS found in endothelial cells promotes vasodilation and may play a beneficial role following a stroke by enhancing reperfusion. NO diffuses freely across membranes and reacts with superoxide to produce peroxynitrite, another highly reactive free radical [91]. Both ROS and reactive nitrogen species are involved in activating several pathways involved in cell death following stroke, including apoptosis and inflammation. Lipid peroxidation also appears to play a prominent role in the pathogenesis of stroke. The mechanism whereby membrane lipid peroxidation induces neuronal apoptosis involves generation of an aldehyde called 4 hydroxynonenal, which covalently modifies membrane transporters such as $\mathrm{Na}^{+} / \mathrm{K}^{+}$ATPase, glucose transporter and glutamate transporter, thereby impairing their function $[87,92]$.

\section{Inflammation}

Besides its neurotoxic activity, calcium and free radicals can also activate inflammatory transcription factors, including $\mathrm{NF} \kappa \mathrm{B}$ [93]. These induce the expression of inflammatory cytokines (e.g. IL-1 $\beta$, IL- 6 and TNF), chemokines (e.g. monocyte chemotactic protein-1, MCP1) and endothelial cell adhesion molecules (e.g. selectins and inter-cellular adhesion molecule 1, ICAM-1) among others [94]. There are several resident cell populations within brain tissue able to secrete pro-inflammatory mediators after an ischemic insult, including endothelial cells, astrocytes, microglia and neurons. Activated microglia produce several pro-inflammatory cytokines, as well as toxic metabolites and enzymes, and in addition, astrocytes play an important role in stroke-induced brain inflammation [94]. Because of the mixed nature of microglial and astrocyte products (both destructive and protective factors), the overall role of glial cells may differ at different time points following a stroke, with damaging effects occurring early (hours to days) and protective or regenerative activities occurring later (several days to weeks) [94].

\section{Calorie restriction and ischemic stroke}

The first way in which CR protects from stroke is by preserving a healthy cardiovascular system. In a study of people who had been on a CR diet for an average of six years versus others on a typical American diet, it was found that $\mathrm{CR}$ reduced body fat, blood pressure and serum lipid and lipoprotein levels [95], which are well-known risk factors for ischemic stroke. The positive effects of CR and IF on systemic blood pressure have been extensively studied in animal models [reviewed in 4] and the mechanism seems 
to be mediated either by decreased activity of the sympathetic nervous system $[96,97]$ or by modifications in activity of the hypothalamic-pituitary neuroendocrine pathways [98]. Age-related decrease in cerebral basal blood flow and brain vascular density was shown to be attenuated by CR in rats, and this appears to be mediated by alterations in growth hormone and insulin growth factor 1 (IGF-1) $[99,100]$. In addition, CR improves endothelial function and decreases circulating levels of inflammatory markers, both of which protect from atherosclerosis, a condition which is intimately linked to stroke [101].

However, once an ischemic insult has occurred, the rates of damage and recovery are affected significantly from CR at many different levels. This is because protective mechanisms are up-regulated by $\mathrm{CR}$ and those mechanisms that are down-regulated by CR are detrimental for stroke outcome. In this sense CR has a hormetic or preconditioning effect, which consists on subjecting the brain to small, harmless insults in order to induce tolerance to ischemia. CR restricts the number of nutrients that reach the brain cells and as a consequence switches on the defence machinery required to protect the cells from lack of nutrients. As a result, cells are now prepared to receive a more severe insult and as a consequence protected from it when it happens. CR pleiotropic effects protect the brain from ischemia by targeting excitotoxicity, oxidative damage, apoptosis, inflammation and autophagy.

\section{Excitotoxicity}

CR has been shown to up-regulate mechanisms that protect the cells from glutamate excitotoxicity. At the tissue level, it increases the efficiency of astrocytes at taking up glutamate, reducing its availability and subsequent neuronal damage [102], which could be beneficial in the case of ischemia. Besides, once the neuron suffers from glutamate toxicity, all the pathways previously up-regulated by $\mathrm{CR}$ come to the rescue, improving the outcome by protecting neurons from cell death. In a mouse model of focal ischemia, mice subjected to IF displayed a smaller infarct volume, and this correlated with higher levels of BDNF, Hsp70, GRP78, HO-1 and other protective factors (Figure 2) [47]. The same is true for CR [103]. BDNF, which is up-regulated after ischemic stroke [104], has been shown to decrease the levels of extracellular glutamate in rat brain if applied 2 hours before an ischemic insult, and to counteract the tendency of inhibitory GABA receptors to reduce in number after ischemia, minimizing as a result the toxic effects of glutamate [105]. The chaperone Hsp70, which is also induced by ischemia [106], has a role in the protection of NMDA receptors and as such contributes to their normal function in toxic conditions. It also protects the presynaptic terminal by maintaining ion channel proteins in the presence of toxic levels of glutamate [107]. The endoplasmic

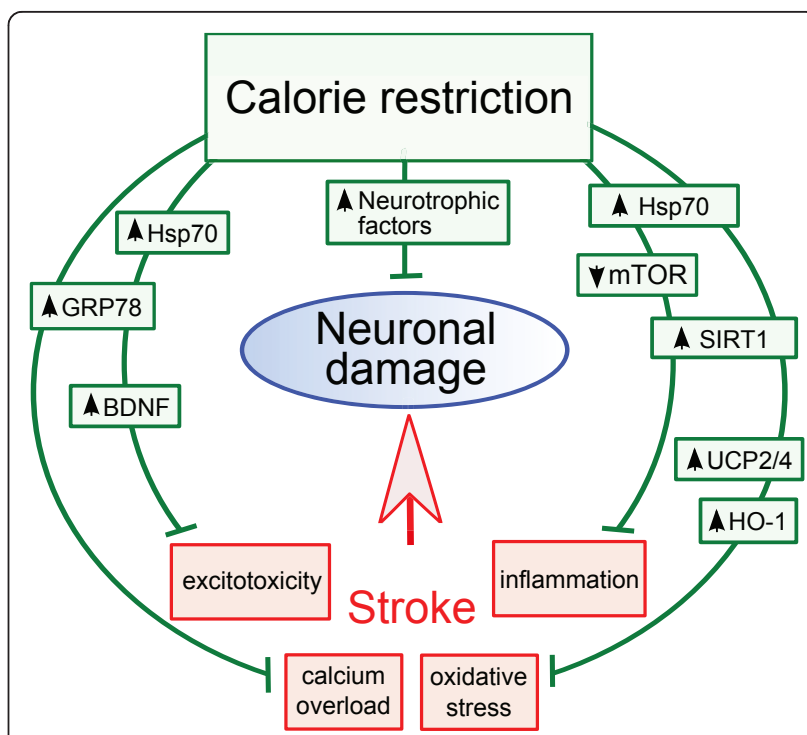

Figure 2 Protective mechanisms of calorie restriction against neuronal cell death in stroke. Stroke acts in detriment of neuronal health by different mechanisms, including exicitotoxicity, calcium overload, oxidative stress and inflammation, which can culminate in neuronal apoptosis. CR prepares neurons to bear each of these forms of stress by modifying the levels of key stressresponse proteins. Certain proteins are up-regulated, such as the chaperones GRP78 and Hsp70, which protect from calcium overload and inflammation; neurotrophic factors such as BDNF, whose role is to protect the cells from excitotoxicity but are also key promoters of neurogenesis after stroke; SIRT1, a central mediator of many CR beneficial effects such as resistance to oxidative stress and moderation of inflammation (through its down-regulation of NFB); UCPs, which are thought to decrease the generation of ROS; and HO-1, with anti-oxidant properties. Hence, CR prepares brain cells at many levels to resist stroke-induced neuronal cell death and promote recovery after stroke.

reticulum associated GRP78, in turn, is responsible for maintaining the levels of intracellular calcium despite the insult, as hippocampal neurons treated with siRNA designed to inactivate GRP78 displayed higher levels of intracellular calcium upon glutamate treatment than control neurons, which is consistent with a role of calcium from the endoplasmic reticulum in excitotoxicity [108]. 2-deoxy-D-glucose, a molecule with similar neuroprotective effects as CR, increased the levels of GRP78, minimized the increase in intracellular calcium and protected from excitotoxicity [109]. Therefore, some of the proteins up-regulated by CR or IF can directly diminish the levels of glutamate excitotoxicity on neurons.

\section{Oxidative damage and apoptosis}

As seen previously, the induction of protective mechanisms by CR accounts for lower basal levels of oxidative stress. However, these mechanisms must also be able to block the generation of ROS and minimize oxidative stress in ischemia to be useful in the protection of the 
brain from an ischemic insult. A central mediator of the protection from ROS in the brain is HO-1, which is induced by hypoxia, has direct antioxidant functions in the ischemic brain [110] and is up-regulated by IF (Figure 2) [47]. However, the lower oxidative damage encountered in neurons after stroke in CR animals, is not mainly caused by ROS scavenging but by a lower production of ROS. In this regard there is emerging evidence of the relevance of uncoupling proteins, as increased UCP2, 3 , and brain-specific UCP4, gene transcription by CR have been shown in human skeletal muscle and brain respectively [39,111]. Overexpression of UCP2 in mice diminished neuronal damage after stroke by inhibiting generation of ROS and preventing apoptosis [40], while overexpression of UCP4 had similar effects in neurons subjected to toxins $[39,112]$. Besides, knock-down of UCP4 in primary hippocampal neurons increased mitochondrial calcium accumulation and cell death [39]. These effects were partly mediated by their prevention of ROS release, consequence of their uncoupling activity, but also by a more direct anti-apoptotic activity.

Both oxidative damage and apoptosis are direct consequences of the exicitotoxic stress imposed on neurons by ischemia, and neurotrophins [113], heat shock proteins [114], and other factors such as HO-1 [115] are known to protect cells from apoptosis. However, most of the current research interest is centred on SIRT1 as the central mediator of the defence against oxidative stress and apoptosis caused by ischemia. SIRT1 has been proposed to mediate neuron survival based on its broad deacetylase activity and has been linked to a positive stroke outcome. SIRT1 function as a deacetylase directly inhibits p53-dependent apoptosis in cortical neurons, and forkhead box (Fox) O3-dependent apoptosis in cerebellar granule neurons, when treated with DNA-damaging, apoptosis promoting agents [116-118]. Affecting either of these transcription factors has positive effects on stroke, as both p53 and FoxO3 have been found to promote cell death upon ischemic insult in vitro $[119,120]$ and in vivo [121-123]. Another substrate of SIRT1 is the relA subunit of $\mathrm{NF} \kappa \mathrm{B}$, which as a result fails to activate transcription of proapoptotic proteins in response to ischemia in vivo and in vitro [124]. SIRT1 also prevents apoptosis by activating the repair protein Ku70 following DNA damage. Under conditions of oxidative stress, Ku70 acetylates, which prevents its ability to sequester the proapoptotic factor Bax, but SIRT1 deacetylates Ku70, which allows it to bind Bax, disabling its apoptotic function [125,126]. This function of $\mathrm{Ku} 70$, whose levels increase after an ischemic insult, has been linked to a decrease in apoptosis after neonatal rat ischemia [127], and a Bax-inhibiting peptide, based on the Bax-Ku70 inhibiting domain, has proved to inhibit apoptosis and improve neurological outcome in rats subjected to global cerebral ischemia [128].
Another protein that prevents apoptosis in stroke, whose deacetylation is mediated by SIRT1, is PGC-1 $\alpha$. SIRT1 not only strongly activates PGC-1 $\alpha$ by deacetylation but it also increases protein levels [129]. PGC-1 $\alpha$, which is also activated directly by oxidative stress, is responsible for protecting neurons from the excitotoxic effects of ischemia. PGC-1 $\alpha$ has been shown to be induced after transient global ischemia, where it protects hippocampal neurons from delayed cell death, and knocking down the gene results in lower expression of UCP2 and the antioxidant enzyme superoxide dismutase 2 (SOD2) leading to neuronal death from oxidative stress [130]. Besides, there is in vitro evidence that an increase in PGC-1 $\alpha$ in neurons subjected to oxygen and glucose deprivation results in the activation of NMDA receptors and inhibits the expression of p38 and ERK MAPK, protecting the neurons from death [131].

Surprisingly, despite its pleiotropic effects on the outcome of stroke, the effect of SIRT1 on recovery from an ischemic insult is not clear. There is evidence that SIRT1 +/- mice have a significantly worse outcome from focal ischemia [132], and drugs such as icariin and resveratrol that increase SIRT1 levels are protective $[133,134]$. However, another study reported the positive effects of nicotinamide, an inhibitor of SIRT1, on the outcome of brain ischemia, and the explanation given is that SIRT1 is a $\mathrm{NAD}^{+}$-dependent enzyme, and therefore in a moment of extreme nutrient deficiency such as stroke, the detrimental effects of its high energy consumption outweigh its aforementioned beneficial effects [135]. On another note, it has been reported that SIRT1's effects on neuroprotection might not be related to its deacetylase activity, as SIRT1's mutations lacking this activity continued to be protective in a model of low potassium-induced neuronal apoptosis [136]. Significant research effort is currently being applied to the understanding of the complexities of SIRT1 in the modulation of protection mechanisms following ischemia and the therapeutic possibilities of the enhancement of its activity.

\section{Inflammation and autophagy}

The positive effects of CR on inflammation and its impact on stroke outcome are remarkable. On one side, having low basal levels of inflammatory cytokines in the circulation decreases susceptibility to stroke [137]. On the other side, CR and IF suppress the overproduction of inflammatory cytokines that is common after ischemic stroke (Figure 2) [47] and which is known to some extent to worsen stroke outcome [138]. SIRT1 and its inhibitory role on $\mathrm{NF} \kappa \mathrm{B}$ could have a lot to do with the lower transcription levels of inflammatory markers seen after stroke in CR organisms. However, another mediator is mTOR, a kinase which, as explained previously, has an important role in inhibiting autophagy and inflammation [74]. mTOR plays a role in cell growth, but it also has a 
function in post-mitotic cells such as neurons, and recently, evidence was shown for increased autophagy after only 48 hours of CR in cortical and Purkinje neurons [79], which correlated with decreased levels of mTOR. The function of autophagy in neurons is to dispose of toxins or damaged mitochondria and it is thought to play an important part in cellular detoxification in stroke. Supporting evidence for the role of autophagy in stroke comes from an in vivo model of transient focal ischemia, where autophagy was detected one day after the insult and then decreased over a period of six days [139]. However, evidence also suggests that autophagy could lead to neuronal death, promoting the assumption that autophagy is a tightly regulated balance that can go one way or another $[140,141]$. Another consequence of mTOR inhibition, as shown by treatment of cultured brain slices with its inhibitor rapamycin, is the suppression of the detrimental post-ischemic long-term potential, but without affecting synaptic plasticity [142], which would otherwise lead to apoptosis. mTOR inhibition also contributes to a positive stroke outcome by decreasing inflammation and immune system activation (Figure 2) [143]. This is evident even in microglia, where mTOR has an effect on activation by hypoxia which is downstream from iNOS and forms part of the PI3K/Akt pathway. This effect, in the case of ischemia, could be responsible for the release of inflammatory molecules by microglia with neuronal death as a result of this inflammation [144].

\section{Other effects of CR in stroke Neurogenesis and angiogenesis}

These two processes are essential for the reconstruction of brain tissue after stroke, which requires the generation of new neurons and neuronal connections as well as the irrigation of these neurons. The primary mediators of ischemic tissue recovery after stroke are BDNF and vascular endothelial growth factor (VEGF). It has been shown that the rate of neuronal production is enhanced after stroke and traumatic brain injury (reviewed in [145]), and BDNF, the mediator of neurogenesis in rodent models of stroke, is upregulated by CR [146]. Moreover, it has been shown that $25 \% \mathrm{CR}$ for three months accounts for increased circulating levels of BDNF in obese humans. VEGF, like other angiogenic factors, is also essential for the recovery of brain tissue, as blood vessel formation has important functions in revascularization of the tissue as well as secretion of growth factors and chemokines which support the survival of new neurons. VEGF expression, enhanced by the hypoxia induced factor 1 alpha (HIF-1 $\alpha$ ) increases with ischemia and contributes to neuroprotection, neurogenesis and angiogenesis [147], as well as blood brain barrier protection. Besides, VEGF is upregulated by CR mimetic resveratrol, which also upregulates other important angiogenic protein, matrix metalloproteinase 2 (MMP-2) [148]. Together they contribute to blood vessel formation in the post-ischemic tissue. Another mediator of revascularization enhanced by CR is adiponectin, which upon ischemic insult increases angiogenesis mediated by activation of AMPK and eNOS, as has been observed in hindlimb ischemia [149]. Adiponectin, a metabolic modulator produced in adipose tissue whose circulating levels are increased in CR and IF [150,151], has also been found to have a positive effect in the recovery from brain ischemia [152].

\section{Regulation of circulating stress hormones}

One of the ways in which CR and IF have been shown to improve the outcome of stroke is through endocrine regulation. Adrenocorticotropic hormone (ACTH) shows an interesting pattern in rats: basal levels are higher under IF, but under stress conditions the increase is smaller than in control animals, suggesting an improved response to stress [98]. Since levels of ACTH and the hormone it induces, cortisol, increase dramatically after stroke and have been correlated with lesion size and neurological deficit in human patients $[153,154]$, smaller increases of these hormones after stroke would seem to be beneficial. It has also been shown that CR down-regulates somatotropic signalling in mice [155], and that mice deficient in growth hormone show an increase in life span, just like those subjected to CR. Moreover, mice deficient in growth hormone that undergo CR do not show any further extension in life span, suggesting a partial dependency between both mechanisms which is mediated by insulin-like growth factor I and insulin [156].

\section{Age modifies cell stress pathways and stroke outcome}

Because aging is a major risk factor for stroke, and stroke outcome is poorer in the elderly, our group recently tested the hypothesis that aging impairs the ability of brain cells to respond adaptively to IF and so to survive a stroke after this regimen. Our findings suggested that aging compromises the ability of energy restriction to protect the brain against ischemic injury and improve functional outcome in stroke. The neuroprotective effect of IF was robust in young mice, was diminished in middle-aged mice, and was lacking in old mice (Figure 3) [47]. Our analysis of neurotrophic factors, stress resistance proteins, and cytokines suggests mechanisms by which aging impairs the ability of IF to protect brain cells against a stroke. Levels of BDNF and basic fibroblast growth factor (bFGF) were diminished in the cortex and striatum of old mice compared with young mice. The amounts of BDNF and bFGF were increased by IF to much higher levels in young compared with middle-aged and old mice [47]. Furthermore, levels of cellular stress protection proteins examined (Hsp70, GRP78, and 
$\mathrm{HO}-1)$ were elevated in response to IF and stroke in young mice, but with greatly diminished responses in middle-aged and old mice [47]. In addition, proinflammatory cytokines TNF and IL-6 levels increased during aging, and decreased in response to IF, particularly in young and middle-aged mice [47]. These findings suggest that reduction in dietary energy intake differentially modulates neurotrophic and inflammatory pathways to protect neurons against ischemic injury and these beneficial effects of IF are compromised during aging (Figure 3).

\section{Concluding Remarks}

The results reported in this review provide evidence to confirm CR as an easy, cost-effective and efficient measure not only for the prevention of stroke, but also for the reduction of damage should stroke occur. On the other side, there is little evidence on the efficacy of CR as

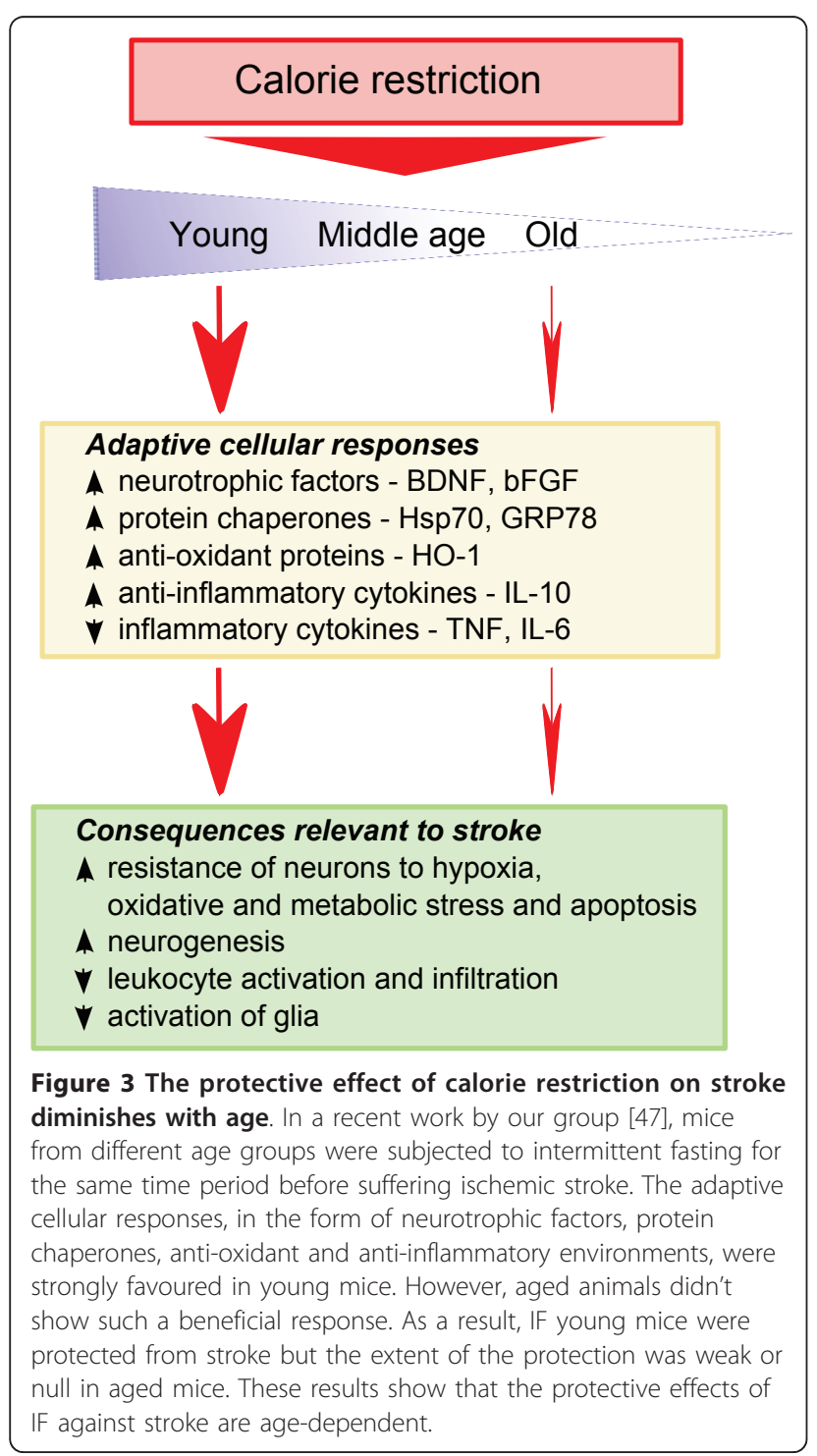

a treatment for stroke. One study reported the neuroprotective benefits of CR after traumatic brain injury in rats, showing that, in this context, 24 hours of fasting after a moderate injury resulted in lower oxidative stress and calcium influx, and improved mitochondrial function [157]. Experiments by another group on rat myocardial ischemia followed by IF revealed improved heart function and angiogenesis, and lower apoptotic rates in the IF rats compared to the control group. These effects were mediated, among others, by BDNF and VEGF [158]. A similar, positive result was encountered in rats subjected to spinal cord injury, where those that underwent IF after the procedure showed improved plasticity and recovery of neurons, accompanied by a 2 to 6 -fold increase in TrkB, the BDNF receptor [159]. These results contrast with those obtained in a gerbil model of global ischemia (5 minutes followed by reperfusion), in which no improvement was found in animals subjected to CR after the intervention [160]. These studies, however, are promising enough to warrant additional research to find out how best, and to what extent, CR can help recover from stroke after the injury has occurred.

\section{Acknowledgements \\ This work was supported by an Australian Research Council Future Fellowship [FT100100427].}

\section{Author details}

${ }^{1}$ School of Biomedical Sciences, The University of Queensland, St Lucia, QLD 4072, Australia. ${ }^{2}$ Department of Neurology, University Clinic HamburgEppendorf, Martinistr, 52, D-20246 Hamburg, Germany.

\section{Authors' contributions}

SM has been involved in literature search and writing as well as drafting the manuscript. TM has been involved in drafting the manuscript. MG has been involved in drafting the manuscript. TVA has been involved in literature search and writing as well as drafting the manuscript and has given final approval. All authors read and approved the final manuscript.

\section{Competing interests}

The authors declare that they have no competing interests.

Received: 2 August 2011 Accepted: 12 September 2011 Published: 12 September 2011

\section{References}

1. Masoro EJ: Subfield history: caloric restriction, slowing aging, and extending life. Sci Aging Knowledge Environ 2003, 2003(8):RE2.

2. Ye J, Keller JN: Regulation of energy metabolism by inflammation: a feedback response in obesity and calorie restriction. Aging 2010, 2(6):361-368.

3. Sohal RS, Weindruch R: Oxidative stress, caloric restriction, and aging. Science 1996, 273(5271):59-63.

4. Mattson MP, Wan R: Beneficial effects of intermittent fasting and caloric restriction on the cardiovascular and cerebrovascular systems. J Nutr Biochem 2005, 16(3):129-137.

5. Bruce-Keller AJ, Umberger G, McFall R, Mattson MP: Food restriction reduces brain damage and improves behavioral outcome following excitotoxic and metabolic insults. Ann Neurol 1999, 45(1):8-15.

6. Greene AE, Todorova MT, McGowan R, Seyfried TN: Caloric restriction inhibits seizure susceptibility in epileptic EL mice by reducing blood glucose. Epilepsia 2001, 42(11):1371-1378. 
7. Jamrozik K, Broadhurst RJ, Anderson CS, Stewart-Wynne EG: The role of lifestyle factors in the etiology of stroke. A population-based casecontrol study in Perth, Western Australia. Stroke 1994, 25(1):51-59.

8. Zheng Z, Lee JE, Yenari MA: Stroke: molecular mechanisms and potential targets for treatment. Curr Mol Med 2003, 3(4):361-372.

9. McCay CM, Crowell MF, Maynard LA: The effect of retarded growth upon the length of life span and upon the ultimate body size. Nutrition 1935, 10(1):63-79.

10. McDonald RB, Ramsey Jj: Honoring Clive McCay and 75 years of calorie restriction research. J Nutr 2010, 140(7):1205-1210.

11. McCay CM, Maynard LA, Sperling G, Barnes LL: Retarded growth, life span, ultimate body size and age changes in the albino rat after feeding diets restricted in calories. Nutrition 1939, 18(1):1-13.

12. Riesen $\mathrm{WH}$, et al: The effect of restricted caloric intake on the longevity of rats. Am J Physiol 1947, 148(3):614-617.

13. Weindruch R, Walford RL: Dietary restriction in mice beginning at 1 year of age: effect on life-span and spontaneous cancer incidence. Science 1982, 215(4538):1415-1418

14. Gerbase-DeLima M, Liu RK, Cheney KE, Mickey R, Walford RL: Immune function and survival in a long-lived mouse strain subjected to undernutrition. Gerontologia 1975, 21(4):184-202.

15. Colman RJ, Anderson RM, Johnson SC, Kastman EK, Kosmatka KJ, Beasley TM, Allison DB, Cruzen C, Simmons HA, Kemnitz JW, Weindruch R: Caloric restriction delays disease onset and mortality in rhesus monkeys. Science 2009, 325(5937):201-204.

16. Rezzi S, Martin FP, Shanmuganayagam D, Colman RJ, Nicholson JK, Weindruch R: Metabolic shifts due to long-term caloric restriction revealed in nonhuman primates. Exp Gerontol 2009, 44(5):356-362.

17. Lane MA, Baer DJ, Rumpler WW, Weindruch R, Ingram DK, Tilmont EM, Cutler RG, Roth GS: Calorie restriction lowers body temperature in rhesus monkeys, consistent with a postulated anti-aging mechanism in rodents. Proc Natl Acad Sci USA 1996, 93(9):4159-4164.

18. Zainal TA, Oberley TD, Allison DB, Szweda LI, Weindruch R: Caloric restriction of rhesus monkeys lowers oxidative damage in skeletal muscle. FASEB J 2000, 14(12):1825-1836.

19. Yu BP, Chung HY: Stress resistance by caloric restriction for longevity. Ann N Y Acad Sci 2001, 928:39-47.

20. Nikolich-Zugich J, Messaoudi I: Mice and flies and monkeys too: caloric restriction rejuvenates the aging immune system of non-human primates. Exp Gerontol 2005, 40(11):884-893.

21. Swindell WR: Genes regulated by caloric restriction have unique roles within transcriptional networks. Mech Ageing Dev 2008, 129(10):580-592.

22. Anson RM, Guo Z, de Cabo R, lyun T, Rios M, Hagepanos A, Ingram DK, Lane MA, Mattson MP: Intermittent fasting dissociates beneficial effects of dietary restriction on glucose metabolism and neuronal resistance to injury from calorie intake. Proc Natl Acad Sci USA 2003, 100(10):6216-6120.

23. Johnson JB, Laub DR, John S: The effect on health of alternate day calorie restriction: eating less and more than needed on alternate days prolongs life. Med Hypotheses 2006, 67(2):209-211.

24. Young JB, Mullen D, Landsberg L: Caloric restriction lowers blood pressure in the spontaneously hypertensive rat. Metabolism 1978, 27(12):1711-1714.

25. Albanes D: Total calories, body weight, and tumor incidence in mice. Cancer Res 1987, 47(8):1987-1992.

26. Lee JH, Jung KJ, Kim JW, Kim HJ, Yu BP, Chung HY: Suppression of apoptosis by calorie restriction in aged kidney. Exp Gerontol 2004, 39(9):1361-1368

27. Shelton LM, Huysentruyt LC, Mukherjee P, Seyfried TN: Calorie restriction as an anti-invasive therapy for malignant brain cancer in the VM mouse. ASN Neuro 2010, 2(3):e00038.

28. Harman D: Aging: a theory based on free radical and radiation chemistry. J Gerontol 1956, 11(3):298-300.

29. Ku HH, Brunk UT, Sohal RS: Relationship between mitochondrial superoxide and hydrogen peroxide production and longevity of mammalian species. Free Radic Biol Med 1993, 15(6):621-627.

30. Barnham KJ, Masters CL, Bush Al: Neurodegenerative diseases and oxidative stress. Nat Rev Drug Discov 2004, 3(3):205-214.

31. Sohal RS, Agarwal S, Candas M, Forster MJ, Lal H: Effect of age and caloric restriction on DNA oxidative damage in different tissues of C57BL/6 mice. Mech Ageing Dev 1994, 76(2-3):215-224.
32. Peters O, Back T, Lindauer U, Busch C, Megow D, Dreier J, Dirnagl U: Increased formation of reactive oxygen species after permanent and reversible middle cerebral artery occlusion in the rat. I Cereb Blood Flow Metab 1998, 18(2):196-205.

33. Domínguez C, Delgado P, Vilches A, Martín-Gallán P, Ribó M, Santamarina E, Molina C, Corbeto N, Rodríguez-Sureda V, Rosell A, Alvarez-Sabín J, Montaner J: Oxidative stress after thrombolysis-induced reperfusion in human stroke. Stroke 2010, 41(4):653-660.

34. Gredilla R, Barja G: Minireview: the role of oxidative stress in relation to caloric restriction and longevity. Endocrinology 2005, 146(9):3713-3717.

35. Bevilacqua L, Ramsey JJ, Hagopian K, Weindruch R, Harper ME: Long-term caloric restriction increases UCP3 content but decreases proton leak and reactive oxygen species production in rat skeletal muscle mitochondria. Am J Physiol Endocrinol Metab 2005, 289(3):E429-438

36. Sanz A, Caro P, Ibañez J, Gómez J, Gredilla R, Barja G: Dietary restriction at old age lowers mitochondrial oxygen radical production and leak at complex I and oxidative DNA damage in rat brain. I Bioenerg Biomembr 2005, 37(2):83-90

37. Caldeira da Silva CC, Cerqueira FM, Barbosa LF, Medeiros MH, Kowaltowski AJ: Mild mitochondrial uncoupling in mice affects energy metabolism, redox balance and longevity. Aging Cell 2008, 7(4):552-560.

38. Keipert S, Klaus S, Heldmaier G, Jastroch M: UCP1 ectopically expressed in murine muscle displays native function and mitigates mitochondrial superoxide production. Biochim Biophys Acta 2010, 1797(2):324-330.

39. Liu D, Chan SL, de Souza-Pinto NC, Slevin JR, Wersto RP, Zhan M, Mustafa K, de Cabo R, Mattson MP: Mitochondrial UCP4 mediates an adaptive shift in energy metabolism and increases the resistance of neurons to metabolic and oxidative stress. Neuromolecular Med 2006, 8(3):389-414.

40. Mattiasson G, Shamloo M, Gido G, Mathi K, Tomasevic G, Yi S, Warden $\mathrm{CH}_{\text {, }}$ Castilho RF, Melcher T, Gonzalez-Zulueta M, Nikolich K, Wieloch T: Uncoupling protein-2 prevents neuronal death and diminishes brain dysfunction after stroke and brain trauma. Nat Med 2003, 9(8):1062-1068.

41. Nakase T, Yoshida $Y$, Nagata K: Amplified expression of uncoupling proteins in human brain ischemic lesions. Neuropathology 2007, 27(5):442-447.

42. Kwok KH, Ho PW, Chu AC, Ho JW, Liu HF, Yiu DC, Chan KH, Kung MH, Ramsden DB, Ho SL: Mitochondrial UCP5 is neuroprotective by preserving mitochondrial membrane potential, ATP levels, and reducing oxidative stress in MPP+ and dopamine toxicity. Free Radic Biol Med 2010, 49(6):1023-1035

43. Chu AC, Ho PW, Kwok KH, Ho JW, Chan KH, Liu HF, Kung MH, Ramsden DB, Ho SL: Mitochondrial UCP4 attenuates MPP+ - and dopamine-induced oxidative stress, mitochondrial depolarization, and ATP deficiency in neurons and is interlinked with UCP2 expression. Free Radic Biol Med 2009, 46(6):810-820.

44. Lü JM, Lin PH, Yao Q, Chen C: Chemical and molecular mechanisms of antioxidants: experimental approaches and model systems. J Cell Mol Med 2010, 14(4):840-860

45. Weindruch R, Kayo T, Lee CK, Prolla TA: Microarray profiling of gene expression in aging and its alteration by caloric restriction in mice. $J$ Nutr 2001, 131(3):918S-923S.

46. Sohal RS, Ku HH, Agarwal S, Forster MJ, Lal H: Oxidative damage, mitochondrial oxidant generation and antioxidant defenses during aging and in response to food restriction in the mouse. Mech Ageing Dev 1994, 74(1-2):121-133.

47. Arumugam TV, Phillips TM, Cheng A, Morrell CH, Mattson MP, Wan R: Age and energy intake interact to modify cell stress pathways and stroke outcome. Ann Neurol 2010, 67(1):41-52.

48. Canto C, Auwerx J: PGC-1alpha, SIRT1 and AMPK, an energy sensing network that controls energy expenditure. Curr Opin Lipidol 2009, 20(2):98-105.

49. Nisoli E, Tonello C, Cardile A, Cozzi V, Bracale R, Tedesco L, Falcone S, Valerio A, Cantoni O, Clementi E, Moncada S, Carruba MO: Calorie restriction promotes mitochondrial biogenesis by inducing the expression of eNOS. Science 2005, 310(5746):314-317.

50. Wu Z, Puigserver P, Andersson U, Zhang C, Adelmant G, Mootha V, Troy A, Cinti S, Lowell B, Scarpulla RC, Spiegelman BM: Mechanisms controlling mitochondrial biogenesis and respiration through the thermogenic coactivator PGC-1. Cell 1999, 98(1):115-124.

51. Masoro EJ, Yu BP, Bertrand HA: Action of food restriction in delaying the aging process. Proc Natl Acad Sci USA 1982, 79(13):4239-4241. 
52. Qin $W$, Haroutunian V, Katsel P, Cardozo CP, Ho L, Buxbaum JD, Pasinetti GM: PGC-1alpha expression decreases in the Alzheimer disease brain as a function of dementia. Arch Neurol 2009, 66(3):352-361.

53. Cui L, Jeong $H$, Borovecki F, Parkhurst CN, Tanese N, Krainc D: Transcriptional repression of PGC-1alpha by mutant huntingtin leads to mitochondrial dysfunction and neurodegeneration. Cell 2006, 127(1):59-69.

54. Zheng B, Liao Z, Locascio JJ, Lesniak KA, Roderick SS, Watt ML, Eklund AC, Zhang-James Y, Kim PD, Hauser MA, Grünblatt E, Moran LB, Mandel SA, Riederer P, Miller RM, Federoff HJ, Wüllner U, Papapetropoulos S, Youdim MB, Cantuti-Castelvetri I, Young AB, Vance JM, Davis RL, Hedreen JC, Adler CH, Beach TG, Graeber MB, Middleton FA, Rochet JC, Scherzer CR, Global PD, Gene Expression (GPEX) Consortium: PGC-1alpha, a potential therapeutic target for early intervention in Parkinson's disease. Sci Transl Med 2010, 2(52):52ra73.

55. Wareski P, Vaarmann A, Choubey V, Safiulina D, Liiv J, Kuum M, Kaasik A: PGC-1\{alpha\} and PGC-1\{beta\} regulate mitochondrial density in neurons. J Biol Chem 2009, 284(32):21379-21385.

56. Hancock CR, Han DH, Higashida K, Kim SH, Holloszy JO: Does calorie restriction induce mitochondrial biogenesis? A reevaluation. FASEB $J$ 2011, 25(2):785-791.

57. Duan W, Guo Z, Mattson MP: Brain-derived neurotrophic factor mediates an excitoprotective effect of dietary restriction in mice. J Neurochem 2001, 76(2):619-626.

58. Duan W, Lee J, Guo Z, Mattson MP: Dietary restriction stimulates BDNF production in the brain and thereby protects neurons against excitotoxic injury. J Mol Neurosci 2001, 16(1):1-12.

59. Maswood N, Young J, Tilmont E, Zhang Z, Gash DM, Gerhardt GA, Grondin R, Roth GS, Mattison J, Lane MA, Carson RE, Cohen RM, Mouton PR, Quigley C, Mattson MP, Ingram DK: Caloric restriction increases neurotrophic factor levels and attenuates neurochemical and behavioral deficits in a primate model of Parkinson's disease. Proc Natl Acad Sci USA 2004, 101(52):18171-18176.

60. Witte AV, Fobker M, Gellner R, Knecht S, Flöel A: Caloric restriction improves memory in elderly humans. Proc Natl Acad Sci USA 2009, 106(4):1255-1260.

61. Gomez-Pinilla F: The influences of diet and exercise on mental health through hormesis. Ageing Res Rev 2008, 7(1):49-62.

62. Kaplan DR, Miller FD: Neurotrophin signal transduction in the nervous system. Curr Opin Neurobiol 2000, 10(3):381-391.

63. Zuccato C, Cattaneo E: Brain-derived neurotrophic factor in neurodegenerative diseases. Nat Rev Neurol 2009, 5(6):311-322.

64. Airaksinen MS, Saarma M: The GDNF family: signalling, biological functions and therapeutic value. Nat Rev Neurosci 2002, 3(5):383-394

65. Stahl K, Mylonakou MN, Skare $\varnothing$, Amiry-Moghaddam M, Torp R: Cytoprotective effects of growth factors: BDNF more potent than GDNF in an organotypic culture model of Parkinson's disease. Brain Res 2011, 1378:105-118.

66. Gardiner J, Barton D, Overall R, Marc J: Neurotrophic support and oxidative stress: converging effects in the normal and diseased nervous system. Neuroscientist 2009, 15(1):47-61.

67. Blake MJ, Fargnoli J, Gershon D, Holbrook NJ: Concomitant decline in heat-induced hyperthermia and HSP70 mRNA expression in aged rats. Am J Physiol 1991, 260(4 Pt 2):R663-R667.

68. Guo Z, Ersoz A, Butterfield DA, Mattson MP: Beneficial effects of dietary restriction on cerebral cortical synaptic terminals: preservation of glucose and glutamate transport and mitochondrial function after exposure to amyloid beta-peptide, iron, and 3-nitropropionic acid. J Neurochem 2000, 75(1):314-320.

69. Li CY, Lee JS, Ko YG, Kim Jl, Seo JS: Heat shock protein 70 inhibits apoptosis downstream of cytochrome $\mathrm{c}$ release and upstream of caspase-3 activation. J Biol Chem 2000, 275(33):25665-25671.

70. Tantucci M, Mariucci G, Taha E, Spaccatini C, Tozzi A, Luchetti E, Calabresi P, Ambrosini MV: Induction of heat shock protein 70 reduces the alteration of striatal electrical activity caused by mitochondrial impairment. Neuroscience 2009, 163(3):735-740.

71. Vass K, Berger ML, Nowak TS Jr, Welch WJ, Lassmann H: Induction of stress protein HSP70 in nerve cells after status epilepticus in the rat. Neurosci Lett 1989, 100(1-3):259-264.

72. Lee AS: The glucose-regulated proteins: stress induction and clinical applications. Trends Biochem Sci 2001, 26(8):504-510.
73. Wang M, Ye R, Barron E, Baumeister P, Mao C, Luo S, Fu Y, Luo B, Dubeau L, Hinton DR, Lee AS: Essential role of the unfolded protein response regulator GRP78/BiP in protection from neuronal apoptosis. Cell Death Differ 2010, 17(3):488-498.

74. Alirezaei M, Kemball CC, Lindsay Whitton J: Autophagy, inflammation and neurodegenerative disease. Eur J Neurosci 2011, 33(2):197-204.

75. Shen W, Ganetzky B: Autophagy promotes synapse development in Drosophila. J Cell Biol 2009, 187(1):71-79.

76. Martinez-Vicente M, Cuervo AM: Autophagy and neurodegeneration: when the cleaning crew goes on strike. Lancet Neurol 2007, 6(4):352-361.

77. Lipinski MM, Zheng B, Lu T, Yan Z, Py BF, Ng A, Xavier RJ, Li C, Yankner BA, Scherzer CR, Yuan J: Genome-wide analysis reveals mechanisms modulating autophagy in normal brain aging and in Alzheimer's disease. Proc Natl Acad Sci USA 2010, 107(32):14164-14169.

78. Jung $\mathrm{CH}$, Jun $\mathrm{CB}$, Ro SH, Kim YM, Otto NM, Cao J, Kundu M, Kim DH: ULKAtg13-FIP200 complexes mediate mTOR signaling to the autophagy machinery. Mol Biol Cell 2009, 20(7):1992-2003.

79. Alirezaei M, Kemball CC, Flynn CT, Wood MR, Whitton JL, Kiosses WB: Shortterm fasting induces profound neuronal autophagy. Autophagy 2010, 6(6):702-710.

80. Garelick MG, Kennedy BK: TOR on the brain. Exp Gerontol 2011, 46(23):155-163.

81. Nicklas BJ, Ambrosius W, Messier SP, Miller GD, Penninx BW, Loeser RF, Palla S, Bleecker E, Pahor M: Diet-induced weight loss, exercise, and chronic inflammation in older, obese adults: a randomized controlled clinical trial. Am J Clin Nutr 2004, 79(4):544-551.

82. Yeung F, Hoberg JE, Ramsey CS, Keller MD, Jones DR, Frye RA, Mayo MW: Modulation of NF-kappaB-dependent transcription and cell survival by the SIRT1 deacetylase. EMBO J 2004, 23(12):2369-2380

83. Chen J, Zhou Y, Mueller-Steiner S, Chen LF, Kwon H, Yi S, Mucke L, Gan L: SIRT1 protects against microglia-dependent amyloid-beta toxicity through inhibiting NF-kappaB signaling. J Biol Chem 2005, 280(48):40364-40374.

84. Young DA, Nickerson-Nutter CL: mTOR-beyond transplantation. Curr Opin Pharmacol 2005, 5(4):418-423.

85. Arundine M, Tymianski M: Molecular mechanisms of glutamatedependent neurodegeneration in ischemia and traumatic brain injury. Cell Mol Life Sci 2004, 61(6):657-668.

86. Mattson MP: Neuroprotective signal transduction: relevance to stroke. Neurosci Biobehav Rev 1997, 21(2):193-206.

87. Mattson MP, Culmsee C, Yu ZF: Apoptotic and antiapoptotic mechanisms in stroke. Cell Tissue Res 2000, 301(1):173-187.

88. Lipton P: Ischemic cell death in brain neurons. Physiol Rev 1999, 79(4):1431-1568

89. Phillis JW, Horrocks LA, Farooqui AA: Cyclooxygenases, lipoxygenases, and epoxygenases in CNS: their role and involvement in neurological disorders. Brain Res Rev 2006, 52(2):201-243.

90. Green SP, Cairns B, Rae J, Errett-Baroncini C, Hongo JA, Erickson RW, Curnutte JT: Induction of gp91-phox, a component of the phagocyte NADPH oxidase, in microglial cells during central nervous system inflammation. J Cereb Blood Flow Metab 2001, 21(4):374-384.

91. Love S: Oxidative stress in brain ischemia. Brain Pathol 1999, 9(1):119-131.

92. Tang SC, Arumugam TV, Cutler RG, Jo DG, Magnus T, Chan SL, Mughal MR, Telljohann RS, Nassar M, Ouyang X, Calderan A, Ruzza P, Guiotto A, Mattson MP: Neuroprotective actions of a histidine analogue in models of ischemic stroke. J Neurochem 2007, 101(3):729-736.

93. Ridder DA, Schwaninger M: NF-kappaB signaling in cerebral ischemia. Neuroscience 2009, 158(3):995-1006.

94. Wang $Q$, Tang XN, Yenari MA: The inflammatory response in stroke. J Neuroimmunol 2007, 184(1-2):53-68.

95. Fontana L, Meyer TE, Klein S, Holloszy JO: Long-term calorie restriction is highly effective in reducing the risk for atherosclerosis in humans. Proc Natl Acad Sci USA 2004, 101(17):6659-6663.

96. Kishi T, Hirooka Y, Ogawa K, Konno S, Sunagawa K: Calorie restriction inhibits sympathetic nerve activity via anti-oxidant effect in the rostral ventrolateral medulla of obesity-induced hypertensive rats. Clin Exp Hypertens 2011, 33(4):240-245.

97. Kushiro T, Kobayashi F, Osada H, Tomiyama H, Satoh K, Otsuka Y, Kurumatani $\mathrm{H}$, Kajiwara N: Role of sympathetic activity in blood pressure reduction with low calorie regimen. Hypertension 1991, 17(6 Pt 2):965-968. 
98. Wan R, Camandola S, Mattson MP: Intermittent food deprivation improves cardiovascular and neuroendocrine responses to stress in rats. J Nutr 2003, 133(6):1921-1929.

99. Lynch CD, Cooney PT, Bennett SA, Thornton PL, Khan AS, Ingram RL, Sonntag WE: Effects of moderate caloric restriction on cortical microvascular density and local cerebral blood flow in aged rats. Neurobiol Aging 1999, 20(2):191-200.

100. Sonntag WE, Lynch C, Thornton P, Khan A, Bennett S, Ingram R: The effects of growth hormone and IGF-1 deficiency on cerebrovascular and brain ageing. J Anat 2000, , 197 Pt 4: 575-585.

101. Shinmura K, Tamaki K, Bolli R: Short-term caloric restriction improves ischemic tolerance independent of opening of ATP-sensitive $\mathrm{K}+$ channels in both young and aged hearts. J Mol Cell Cardiol 2005, 39(2):285-296.

102. Ribeiro LC, Quincozes-Santos A, Leite MC, Abib RT, Kleinkauf-Rocha J, Biasibetti R, Rotta LN, Wofchuk ST, Perry ML, Gonçalves CA, Gottfried C: Caloric restriction increases hippocampal glutamate uptake and glutamine synthetase activity in Wistar rats. Neurosci Res 2009, 64(3):330-334.

103. Yu ZF, Mattson MP: Dietary restriction and 2-deoxyglucose administration reduce focal ischemic brain damage and improve behavioral outcome: evidence for a preconditioning mechanism. J Neurosci Res 1999, 57(6):830-839.

104. Lindvall O, Ernfors P, Bengzon J, Kokaia Z, Smith ML, Siesjö BK, Persson H: Differential regulation of mRNAs for nerve growth factor, brain-derived neurotrophic factor, and neurotrophin 3 in the adult rat brain following cerebral ischemia and hypoglycemic coma. Proc Natl Acad Sci USA 1992, 89(2):648-652.

105. Sommer C, Kollmar R, Schwab S, Kiessling M, Schäbitz WR: Exogenous brain-derived neurotrophic factor prevents postischemic downregulation of $[3 \mathrm{H}]$ muscimol binding to $\mathrm{GABA}(\mathrm{A})$ receptors in the cortical penumbra. Brain Res Mol Brain Res 2003, 111(1-2):24-30.

106. Franklin TB, Krueger-Naug AM, Clarke DB, Arrigo AP, Currie RW: The role of heat shock proteins Hsp70 and Hsp27 in cellular protection of the central nervous system. Int J Hyperthermia 2005, 21(5):379-392.

107. Mokrushin AA, Pavlinova LI, Plekhanov AY: Heat shock protein HSP70 increases the resistance of cortical cells to glutamate excitotoxicity. Bull Exp Biol Med 2005, 140(1):1-5

108. Yu Z, Luo H, Fu W, Mattson MP: The endoplasmic reticulum stressresponsive protein GRP78 protects neurons against excitotoxicity and apoptosis: suppression of oxidative stress and stabilization of calcium homeostasis. Exp Neurol 1999, 155(2):302-314.

109. Yu ZF, Mattson MP: Dietary restriction and 2-deoxyglucose administration reduce focal ischemic brain damage and improve behavioral outcome: evidence for a preconditioning mechanism. J Neurosci Res 1999 57(6):830-839.

110. Panahian N, Yoshiura M, Maines MD: Overexpression of heme oxygenase1 is neuroprotective in a model of permanent middle cerebral artery occlusion in transgenic mice. J Neurochem 1999, 72(3):1187-1203.

111. Millet L, Vidal H, Andreelli F, Larrouy D, Riou JP, Ricquier D, Laville M, Langin D: Increased uncoupling protein-2 and -3 mRNA expression during fasting in obese and lean humans. J Clin Invest 1997, 100(11):2665-2670.

112. Wei Z, Chigurupati S, Bagsiyao P, Henriquez A, Chan SL: The brain uncoupling protein UCP4 attenuates mitochondrial toxin-induced cell death: role of extracellular signal-regulated kinases in bioenergetics adaptation and cell survival. Neurotox Res 2009, 16(1):14-29.

113. Kim DH, Zhao X: BDNF protects neurons following injury by modulation of caspase activity. Neurocrit Care 2005, 3(1):71-76.

114. Kelly S, Bieneman A, Horsburgh K, Hughes D, Sofroniew MV, McCulloch J, Uney JB: Targeting expression of hsp70i to discrete neuronal populations using the Lmo-1 promoter: assessment of the neuroprotective effects of hsp70i in vivo and in vitro. J Cereb Blood Flow Metab 2001, 21(8):972-981.

115. Imuta N, Hori O, Kitao Y, Tabata Y, Yoshimoto T, Matsuyama T, Ogawa S: Hypoxia-mediated induction of heme oxygenase type I and carbon monoxide release from astrocytes protects nearby cerebral neurons from hypoxia-mediated apoptosis. Antioxid Redox Signal 2007, 9(5):543-552.

116. Brunet A, Sweeney LB, Sturgill JF, Chua KF, Greer PL, Lin Y, Tran H, Ross SE, Mostoslavsky R, Cohen HY, Hu LS, Cheng HL, Jedrychowski MP, Gygi SP,
Sinclair DA, Alt FW, Greenberg ME: Stress-dependent regulation of FOXO transcription factors by the SIRT1 deacetylase. Science 2004, 303(5666):2011-2015.

117. Hasegawa K, Yoshikawa K: Necdin regulates p53 acetylation via Sirtuin1 to modulate DNA damage response in cortical neurons. J Neurosci 2008 , 28(35):8772-8784.

118. Wang F, Nguyen M, Qin FX, Tong Q: SIRT2 deacetylates FOXO3a in response to oxidative stress and caloric restriction. Aging Cell 2007, 6(4):505-514.

119. Halterman MW, Federoff HJ: HIF-1alpha and p53 promote hypoxiainduced delayed neuronal death in models of CNS ischemia. Exp Neurol 1999, 159(1):65-72.

120. Dick O, Bading H: Synaptic activity and nuclear calcium signaling protect hippocampal neurons from death signal-associated nuclear translocation of FoxO3a induced by extrasynaptic N-methyl-D-aspartate receptors. J Biol Chem 2010, 285(25):19354-19361.

121. Leker RR, Aharonowiz M, Greig NH, Ovadia H: The role of p53-induced apoptosis in cerebral ischemia: effects of the p53 inhibitor pifithrin alpha. Exp Neurol 2004, 187(2):478-486.

122. Won CK, Ji HH, Koh PO: Estradiol prevents the focal cerebral ischemic injury-induced decrease of forkhead transcription factors phosphorylation. Neurosci Lett 2006, 398(1-2):39-43.

123. Kuningas $M$, Mägi $R$, Westendorp RG, Slagboom PE, Remm M, van Heemst D: Haplotypes in the human Foxo1a and Foxo3a genes; impact on disease and mortality at old age. Eur J Hum Genet 2007, 15(3):294-301.

124. Lanzillotta A, Sarnico I, Ingrassia R, Boroni F, Branca C, Benarese M, Faraco G, Blasi F, Chiarugi A, Spano P, Pizzi M: The acetylation of RelA in Lys310 dictates the NF-kappaB-dependent response in post-ischemic injury. Cell Death Dis 2010, 1(11):e96.

125. Jeong J, Juhn K, Lee H, Kim SH, Min BH, Lee KM, Cho MH, Park GH, Lee KH: SIRT1 promotes DNA repair activity and deacetylation of Ku70. Exp Mol Med 2007, 39(1):8-13.

126. Cohen HY, Miller C, Bitterman KJ, Wall NR, Hekking B, Kessler B, Howitz KT, Gorospe $M$, de Cabo $R$, Sinclair DA: Calorie restriction promotes mammalian cell survival by inducing the SIRT1 deacetylase. Science 2004, 305(5682):390-392.

127. Meng S, Lin L, Lama S, Qiao M, Tuor UI: Cerebral expression of DNA repair protein, Ku70, and its association with cell proliferation following cerebral hypoxia-ischemia in neonatal rats. Int J Dev Neurosci 2009, 27(2):129-134.

128. Han B, Wang Q, Cui G, Shen X, Zhu Z: Post-treatment of Bax-inhibiting peptide reduces neuronal death and behavioral deficits following global cerebral ischemia. Neurochem Int 2011, 58(2):224-233.

129. Nemoto S, Fergusson MM, Finkel T: SIRT1 functionally interacts with the metabolic regulator and transcriptional coactivator PGC-1\{alpha\}. J Biol Chem 2005, 280(16):16456-16460.

130. Chen SD, Lin TK, Yang DI, Lee SY, Shaw FZ, Liou CW, Chuang YC Protective effects of peroxisome proliferator-activated receptors gamma coactivator-1alpha against neuronal cell death in the hippocampal CA1 subfield after transient global ischemia. J Neurosci Res 2010, 88(3):605-613.

131. Luo Y, Zhu W, Jia J, Zhang C, Xu Y: NMDA receptor dependent PGC1alpha up-regulation protects the cortical neuron against oxygenglucose deprivation/reperfusion injury. J Mol Neurosci 2009, 39(12):262-268.

132. Wang P, Xu TY, Guan YF, Tian WW, Viollet B, Rui YC, Zhai QW, Su DF, Miao $C Y$ : Nicotinamide phosphoribosyltransferase protects against ischemic stroke through SIRT1-dependent adenosine monophosphateactivated kinase pathway. Ann Neurol 2011, 69(2):360-374.

133. Zhu HR, Wang ZY, Zhu XL, Wu XX, Li EG, Xu Y: Icariin protects against brain injury by enhancing SIRT1-dependent PGC-1alpha expression in experimental stroke. Neuropharmacology 2010, 59(1-2):70-76.

134. Raval AP, Dave KR, Perez-Pinzon MA: Resveratrol mimics ischemic preconditioning in the brain. J Cereb Blood Flow Metab 2006, 26(9):1141-1147.

135. Liu D, Gharavi R, Pitta M, Gleichmann M, Mattson MP: Nicotinamide prevents NAD+ depletion and protects neurons against excitotoxicity and cerebral ischemia: NAD+ consumption by SIRT1 may endanger energetically compromised neurons. Neuromolecular Med 2009, 11(1):28-42. 
136. Pfister JA, Ma C, Morrison BE, D'Mello SR: Opposing effects of sirtuins on neuronal survival: SIRT1-mediated neuroprotection is independent of its deacetylase activity. PLoS One 2008, 3(12):e4090.

137. Chiba T, Ezaki O: Dietary restriction suppresses inflammation and delays the onset of stroke in stroke-prone spontaneously hypertensive rats. Biochem Biophys Res Commun 2010, 399(1):98-103.

138. Lakhan SE, Kirchgessner A, Hofer M: Inflammatory mechanisms in ischemic stroke: therapeutic approaches. J Trans/ Med 2009, 7:97.

139. Tian F, Deguchi K, Yamashita T, Ohta Y, Morimoto N, Shang J, Zhang X, Liu N, Ikeda $Y$, Matsuura T, Abe K: In vivo imaging of autophagy in a mouse stroke model. Autophagy 2010, 6(8):1107-1114.

140. Koike M, Shibata M, Tadakoshi M, Gotoh K, Komatsu M, Waguri S, Kawahara N, Kuida K, Nagata S, Kominami E, Tanaka K, Uchiyama Y: Inhibition of autophagy prevents hippocampal pyramidal neuron death after hypoxic-ischemic injury. Am J Pathol 2008, 172(2):454-469.

141. Rami A, Kogel D: Apoptosis meets autophagy-like cell death in the ischemic penumbra: Two sides of the same coin? Autophagy 2008, 4(4):422-426.

142. Ghiglieri V, Pendolino V, Bagetta V, Sgobio C, Calabresi P, Picconi B: mTOR inhibitor rapamycin suppresses striatal post-ischemic LTP. Exp Neurol 2010, 226(2):328-331

143. Delgoffe GM, Powell JD: mTOR: taking cues from the immune microenvironment. Immunology 2009, 127(4):459-465.

144. Lu DY, Liou HC, Tang CH, Fu WM: Hypoxia-induced iNOS expression in microglia is regulated by the PI3-kinase/Akt/mTOR signaling pathway and activation of hypoxia inducible factor-1alpha. Biochem Pharmacol 2006, 72(8):992-1000

145. Kernie SG, Parent JM: Forebrain neurogenesis after focal Ischemic and traumatic brain injury. Neurobiol Dis 2010, 37(2):267-274

146. Lee J, Duan W, Mattson MP: Evidence that brain-derived neurotrophic factor is required for basal neurogenesis and mediates, in part, the enhancement of neurogenesis by dietary restriction in the hippocampus of adult mice. J Neurochem 2002, 82(6):1367-1375.

147. Sun Y, Jin K, Xie L, Childs J, Mao XO, Logvinova A, Greenberg DA: VEGFinduced neuroprotection, neurogenesis, and angiogenesis after focal cerebral ischemia. J Clin Invest 2003, 111(12):1843-1851.

148. Dong W, Li N, Gao D, Zhen H, Zhang X, Li F: Resveratrol attenuates ischemic brain damage in the delayed phase after stroke and induces messenger RNA and protein express for angiogenic factors. J Vasc Surg 2008, 48(3):709-714.

149. Kondo M, Shibata R, Miura R, Shimano M, Kondo K, Li P, Ohashi T, Kihara S, Maeda N, Walsh K, et al: Caloric restriction stimulates revascularization in response to ischemia via adiponectin-mediated activation of endothelial nitric-oxide synthase. J Biol Chem 2009, 284(3):1718-1724.

150. Zhu M, Miura J, Lu LX, Bernier M, DeCabo R, Lane MA, Roth GS, Ingram DK: Circulating adiponectin levels increase in rats on caloric restriction: the potential for insulin sensitization. Exp Gerontol 2004, 39(7):1049-1059.

151. Wan R, Ahmet I, Brown M, Cheng A, Kamimura N, Talan M, Mattson MP: Cardioprotective effect of intermittent fasting is associated with an elevation of adiponectin levels in rats. J Nutr Biochem 2010, 21(5):413-417.

152. Nishimura M, Izumiya Y, Higuchi A, Shibata R, Qiu J, Kudo C, Shin HK, Moskowitz MA, Ouchi N: Adiponectin prevents cerebral ischemic injury through endothelial nitric oxide synthase dependent mechanisms. Circulation 2008, 117(2):216-223.

153. Fassbender K, Schmidt R, Mossner R, Daffertshofer M, Hennerici M: Pattern of activation of the hypothalamic-pituitary-adrenal axis in acute stroke. Relation to acute confusional state, extent of brain damage, and clinical outcome. Stroke 1994, 25(6):1105-1108.

154. Neidert S, Katan M, Schuetz P, Fluri F, Ernst A, Bingisser R, Kappos L, Engelter ST, Steck A, Muller B, et al: Anterior pituitary axis hormones and outcome in acute ischaemic stroke. J Intern Med 2011, 269(4):420-432.

155. Al-Regaiey KA, Masternak MM, Bonkowski M, Sun L, Bartke A: Long-lived growth hormone receptor knockout mice: interaction of reduced insulin-like growth factor i/insulin signaling and caloric restriction. Endocrinology 2005, 146(2):851-860

156. Bonkowski MS, Rocha JS, Masternak MM, Al Regaiey KA, Bartke A: Targeted disruption of growth hormone receptor interferes with the beneficial actions of calorie restriction. Proc Natl Acad Sci USA 2006, 103(20):7901-7905
157. Davis LM, Pauly JR, Readnower RD, Rho JM, Sullivan PG: Fasting is neuroprotective following traumatic brain injury. J Neurosci Res 2008, 86(8):1812-1822

158. Katare RG, Kakinuma Y, Arikawa M, Yamasaki F, Sato T: Chronic intermittent fasting improves the survival following large myocardial ischemia by activation of BDNF/VEGF/PI3K signaling pathway. J Mol Cell Cardiol 2009, 46(3):405-412.

159. Plunet WT, Streijger F, Lam CK, Lee JH, Liu J, Tetzlaff W: Dietary restriction started after spinal cord injury improves functional recovery. Exp Neurol 2008, 213(1):28-35

160. McEwen BR, Paterson PG: Caloric restriction provided after global ischemia does not reduce hippocampal cornu ammonis injury or improve functional recovery. Neuroscience 2010, 166(1):263-270.

doi:10.1186/2040-7378-3-8

Cite this article as: Manzanero et al:: Calorie restriction and stroke.

Experimental \& Translational Stroke Medicine 2011 3:8.

\section{Submit your next manuscript to BioMed Central and take full advantage of:}

- Convenient online submission

- Thorough peer review

- No space constraints or color figure charges

- Immediate publication on acceptance

- Inclusion in PubMed, CAS, Scopus and Google Scholar

- Research which is freely available for redistribution

Submit your manuscript at www.biomedcentral.com/submit 